\title{
Education Model Study of Local Colleges and Universities based on "MOOC+ Traditional Classroom”
}

\author{
Qingyun Chi ${ }^{1, \text { a }}{ }^{*}$, Zhang Wei ${ }^{2, b}$ \\ ${ }^{1}$ College of Information Science and Engineering, Zaozhuang University, Shandong Province, China \\ ${ }^{2}$ College of Information Science and Engineering, Zaozhuang University, Shandong Province, China \\ a cqysd@163.com, ${ }^{b}$ zz_zhangwei@163.com \\ *corresponding author
}

Keywords: MOOC; Flipped classroom; traditional classroom

\begin{abstract}
With the development of the Internet, MOOC walked into the classroom, derived from many new teaching models, such as the popular flipped classroom, micro class, private classes. The articles points out teaching difficulties in local colleges and universities, and analyse the confusion of local colleges and universities, according to my school teaching characteristics, conceived "MOOC + traditional classroom" is a new teaching model. MOOC can combine the advantages of diversity; it is expected to be able to enhance the efficiency of local colleges and universities, to get rid of the teaching difficulties and prompt MOOC better in higher education.
\end{abstract}

\section{Introduction}

In 2013, the US New Media Alliance's Horizon Report stated that MOOC is one of the six major information technologies that affect future higher education ${ }^{[1]}$. In recent years, both domestic and foreign, MOOC has become a research hotspot in various fields, and there is a blowout trend. With the improvement of network technology and communication capabilities, MOOC education seeks to complement the shortcomings of traditional education.

Although many scholars have argued that flipping classrooms are conducive to students' more effective learning in the school environment, there are differences in the practice of flipping classroom teaching models in local colleges. Exploring the "MOOC+Traditional Classroom" teaching mode, it is very meaningful to improve the teaching efficiency by changing the teaching methods to the application of talents in local colleges and universities.

\section{2. "Flipped classroom" teaching model in local colleges and universities}

\subsection{Problems in the training of applied talents in local colleges and universities under the background of MOOC}

More and more domestic local colleges and universities are also trying to develop their own MOOC courses to meet the needs of building open courses actively, and to introduce MOOC content into teaching and SPOC teaching, but there are still many problems:

(1) Difficulties in the introduction of talents and tight educational resources have become the shackle of the complete credit system in local schools.

Due to the limitations of teachers and curriculum resources, as well as geographical restrictions, most ordinary colleges and universities in the country are still in the transition period from the academic year to the credit system. In the actual operation process, a sufficient number of course groups cannot be provided. In most courses, the students' self-selected courses and self-determined learning progress cannot be realized, and the students' autonomy, creative learning and personalized development are curbed.

(2) Under the background of "Internet + education", there is a conflict between the independent learning mode of college students and the traditional teaching mode. At present, the teaching of 
many local colleges and universities does not fully consider the new characteristics of the growth environment of college students in the "Internet" era.

(3) Under the era of "mass entrepreneurship and innovation", the concept of innovation and entrepreneurship education in local colleges and universities is not tightly integrated with professional education, and it is out of touch with practice, which cannot meet the needs of local colleges and universities.

In recent years, local colleges and universities have achieved positive results in innovation and entrepreneurship education, but there are also many problems; teachers lack the awareness and ability to carry out innovation and entrepreneurship education, the teaching methods are single, the targeted effectiveness is not strong; the practice platform is short, and the guidance is helpful. Not in place, the innovation and entrepreneurship education system needs to be improved.

The advanced concept and many characteristics of MOOC can make up to some extent the "short board" of innovation and entrepreneurship education in local colleges and universities. The use of MOOC resources can enrich teaching content, enhance teaching effectiveness, effectively guide college students to start businesses, and train more applied talents for the society.

MOOC has played a positive role in the learning attitude and interest of local teachers' college students [1].However, with the rapid development of MOOC, the "paradox" is that although the respondents think that the MOOC form is better than the traditional classroom form, it has not become the main learning method for the learners in the local normal colleges. The learners still use the traditional classroom learning form. Mainly, it shows that online learning habits have not yet been developed, and online education has a long way to go. The change of learning mode is also a test for local college students. Through the three-year tracking survey of "students' acceptance of MOOC", the questionnaire survey results are shown in figure 1.

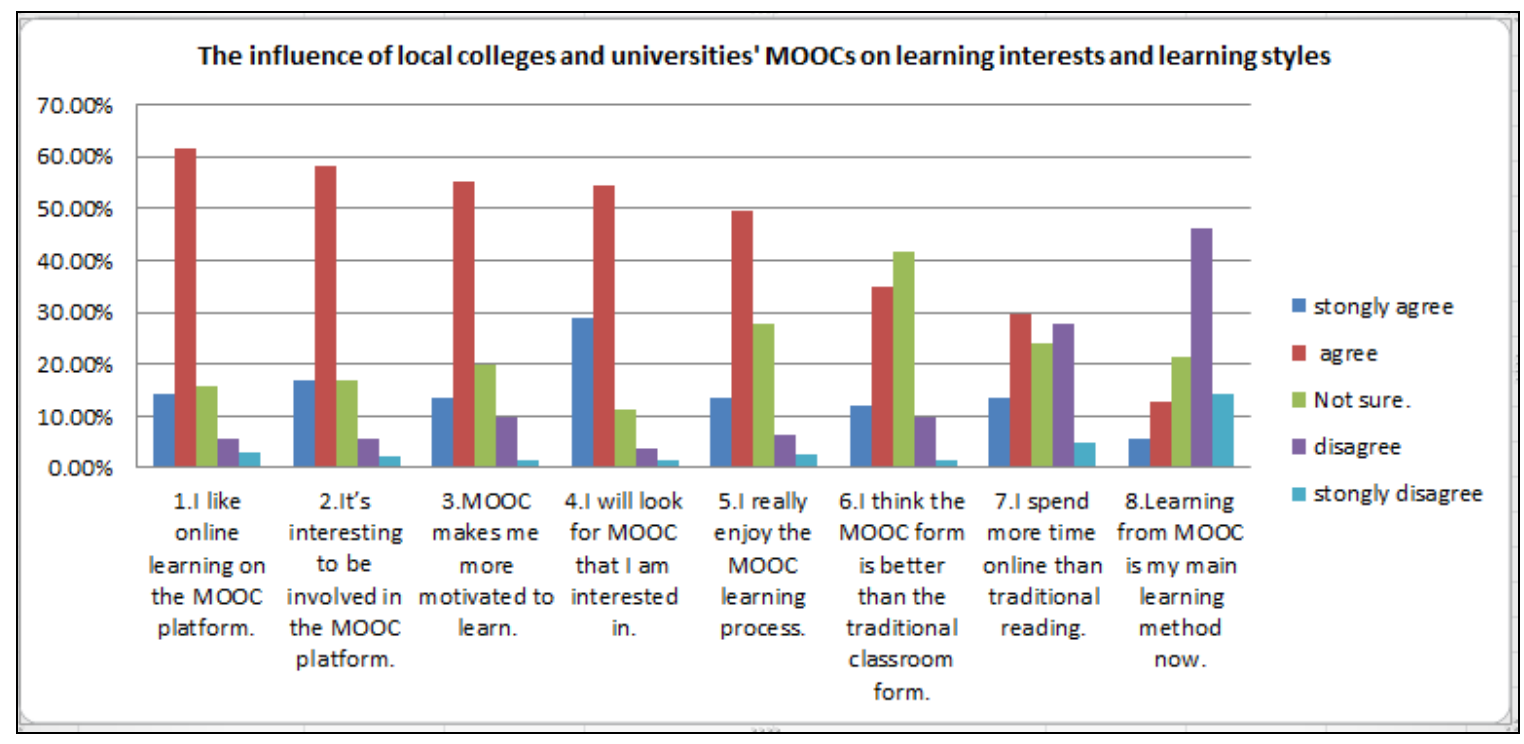

Figure 1 The influence of local colleges and universities' MOOCs on learning interests and learning styles

MOOC also has a great influence on the knowledge construction of local college students. Specifically, mooc has had a significant impact on the learning of "explicit knowledge".92.9\% and $71.6 \%$ of the learners believed that they could learn new knowledge through MOOC, which was significant to improve their professional knowledge. It can be seen that MOOC is effective in learning the "obvious knowledge" of local college students, but not in "knowledge innovation". MOOC learning still stays in the acquisition of knowledge. It can be seen that the problem of deep learning is still the biggest problem affecting the sustainable development of MOOC. Through the three-year tracking survey of "the influence of MOOC on knowledge construction", the questionnaire survey results are shown in figure 2. 


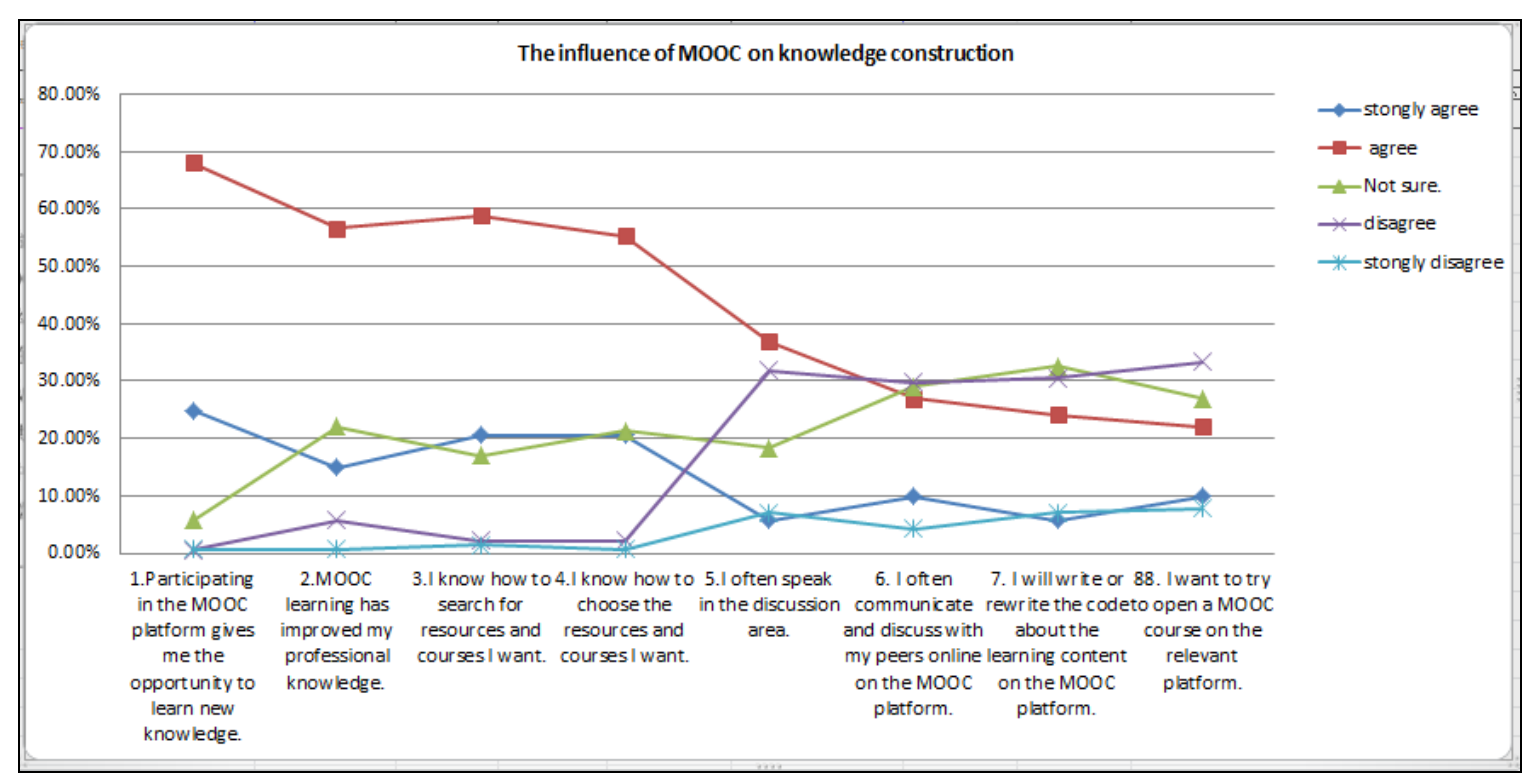

Figure 2 The influence of MOOC on knowledge construction

\subsection{Puzzlement of developing flipped classroom in local colleges and Universities}

In the traditional classroom, we learn new knowledge in class and finish homework consolidation exercises under class. On the contrary, before flipped classroom, students use the network resources to learn the relevant professional knowledge and basic knowledge, complete the preview of knowledge, mainly discuss in class time, and then complete the relevant knowledge consolidation exercises to solve the problems encountered in the process of self-study. Such a learning method has achieved a definite goal and is more conducive to students' learning. The comparison between flipped classroom and traditional classroom is shown in Table 1.

Table 1 Comparison of flipped classroom and traditional classroom

\begin{tabular}{c|c|c}
\hline & Traditional Classroom & Flipped classroom \\
\hline Teacher & $\begin{array}{c}\text { Knowledge transferer+Classroom } \\
\text { manager }\end{array}$ & $\begin{array}{c}\text { Learning instructor、 Learning } \\
\text { facilitator }\end{array}$ \\
\hline Student & Recipient & Active researcher \\
\hline Teaching form & Class explanation Homework & Learning before class Classroom study \\
\hline Class content & Knowledge explanation & Problem exploration \\
\hline $\begin{array}{c}\text { Technical } \\
\text { application }\end{array}$ & Content show & $\begin{array}{c}\text { Self-learning+Communication } \\
\text { reflection }\end{array}$ \\
\hline $\begin{array}{c}\text { Evaluation } \\
\text { method }\end{array}$ & Traditional paper test & \begin{tabular}{c} 
Multi-angle, Diversification \\
\hline
\end{tabular}
\end{tabular}

\section{MOOC+ traditional classroom teaching mode}

On the website of the US Department of Education, the results of the case study on higher education were published publicly from 1996 to 2008. It is believed that only participation in classroom teaching is less efficient, MOOC is second, and MOOC+ classroom teaching is the most efficient. In 2013, the Horizon Report considered that the new model for the future development of educational models should be: MOOC learning, MOOC+ classroom learning and collaborative learning.

Flipped classroom takes a long time to cultivate students 'learning habits, which will cost a lot of material and financial resources and waste teaching time. However, at the same time, we should draw on the characteristics of flipped classroom autonomy, aiming at cultivating students' autonomous learning ability. One is to train students' good habit of thinking and talking in class; the 
other is to guide students and guide them to acquire and use learning resources after class.

MOOC and traditional classroom can complement each other. Our school has less free time for discussion in class. The short MOOC video is played in class, which can set aside a lot of time for students to discuss and stimulate students' interest in learning.

In the MOOC, video is an important form of learning. MOOC and traditional classrooms can be integrated in this following ways.

\subsection{MOOC can be used as a means of knowledge introduction.}

MOOC video can be used as a pre-course guide in teaching. Because there are a lot of teaching resources available in MOOC, in just ten minutes, it can be a demonstration experiment, or it can be a colourful teaching method such as a wonderful lecture from a famous school. Therefore, using MOOC as a classroom introduction will increase students' interest in learning undoubtedly.

\subsection{MOOC can be used as an effective means of preview}

Through MOOC, students can have a general understanding of this course, and they will not lose confidence in learning because of difficulties. Many questions will be raised imperceptibly, thus forming interest and exploration, which is what we pursue in class reform. The comprehensiveness of MOOC $\mathrm{s}$ and the professionalism of the class are just difficult and easy to complement. Meanwhile, students will be more active when taking classes with questions.

\subsection{MOOC can be used as a means of review and enhancement.}

In the traditional classroom, students must have doubts after completing the study. Then, after class, they can review the content of the MOOC lectures repeatedly or through the MOOC communication platform to answer questions, obtain new knowledge from the communication and consolidate the learned content.

\subsection{MOOC can be used as a means of commenting on important and difficult problems.}

Using MOOC to explain the important and difficult problems. Students will be impressed when teachers evaluate difficulties in teaching according to their own teaching experience and play the import MOOC video. For some students who have the ability to learn, there is a need to explore new knowledge and further study. The MOOC platform can provide higher and deeper learning content for these students to learn, so as to give full play to their learning ability.

The knowledge of MOOC is piecemeal and cannot bring students a complete knowledge structure, but our traditional classroom concentrated time learning, teaching continuity is relatively strong, can solve the problem of knowledge fragmentation. Our traditional classroom learning time concentration, teaching continuity, can be a good solution to the problem of knowledge fragmentation.

\section{Conclusions}

The integration of MOOC and traditional classroom teaching can overcome many difficulties in traditional teaching, accelerate the improvement of the overall teaching level in the region, and set up a new knowledge dissemination platform for teachers and students. MOOC+classroom teaching is based on face-to-face teaching and supplemented by MOOC. Outside the classroom, MOOC is used for self-study, and MOOC is a high-quality platform evaluation system to encourage students to learn independently.

\section{References}

[1] Ye Donglian. Research on the Influence of MOOC on Local Normal University Students: Connectivity and Construction [J]. Digital Education, 2016, (5): 35-40. DOI:10.3969/j.issn.20960069.2016.05.007. 
[2] Gao Xinfeng. The design of the climax course of media major based on the flipped classroom mode-Taking the course of "micro-documentary creation" as an example [J]. Modern Educational Technology, 2015, (9): 84-89. DOI: 10.3969/j. Issn.1009-8097.2015.09.013.

[3] Hua Qi, Wang Rui. Practice and Reflection of the Flipping Classroom Teaching Model in Local Colleges and Universities [J]. High Teaching Journal, 2018, (10): 99-101.

[4] Sun Ling. Research on college English flipping classroom based on WeChat in local undergraduate colleges [J]. Times Education, 2017, (19): 59-60. DOI:10.3969/j.issn.16728181.2017.19.044.

[5] Lei Jing. Application Research of "Flip Classroom" Teaching Mode in College Classroom Teaching [J]. Exam Week, 2016, (74): 165-165, 166. DOI:10.3969/j.issn.1673-8918.2016.74.146. 